\title{
An Overview of Wind-Driven Rovers for Planetary Exploration
}

\author{
G. A. Hajos* \\ NASA, Langley Research Center, Hampton, VA 23681 \\ J. A. Jones ${ }^{\dagger}$ and A. Behar, Ph. D. ${ }^{\ddagger}$ \\ Jet Propulsion Laboratory, Pasadena, CA 91101 \\ M. Dodd ${ }^{\S}$ \\ Virginia Air and Space Center, Hampton, VA 23669
}

\begin{abstract}
The use of in-situ propulsion is considered enabling technology for long duration planetary surface missions. Most studies have focused on stored energy from chemicals extracted from the soil or the use of soil chemicals to produce photovoltaic arrays. An older form of in-situ propulsion is the use of wind power. Recent studies have shown potential for wind driven craft for exploration of Mars, Titan and Venus. The power of the wind, used for centuries to power wind mills and sailing ships, is now being applied to modern land craft. Efforts are now underway to use the wind to push exploration vehicles on other planets and moons in extended survey missions. Tumbleweed rovers are emerging as a new type of wind-driven science platform concept. Recent investigations by the National Aeronautics and Space Administration (NASA) and Jet Propulsion Laboratory (JPL) indicate that these light-weight, mostly spherical or quasi-spherical devices have potential for long distance surface exploration missions. As a power boat has unique capabilities, but relies on stored energy (fuel ) to move the vessel, the Tumbleweed, like the sailing ships of the early explorers on earth, uses an unlimited resource - the wind to move around the surface of Mars. This has the potential to reduc the major mass drivers of robotic rovers as well as the power generation and storage systems. Jacques Blamont of JPL and the University of Paris conceived the first documented Mars wind-blown ball in 1977, shortly after the Viking landers discovered that Mars has a thin CO2 atmosphere with relatively strong winds. In 1995, Jack Jones, et al, of JPL conceived of a large wind-blown inflated ball for Mars that could also be driven and steered by means of a motorized mass hanging beneath the rolling axis of the ball. A team at NASA Langley Research Center started a biomimetic Tumbleweed design study in 1998. Wind tunnel and CFD analysis were applied to a variety of concepts to optimize the aerodynamic characteristics of the Tumbleweed Rovers. Bare structures, structures carrying sails and a tumbleweed plant (of the Salsola genus) were tested in Langley's wind tunnels. Thomas Estier of the Swiss Federal Institute of Technology developed a memory metal collapsible structure, the Windball. Numerous other researchers have also suggested spherical rovers.
\end{abstract}

\section{Introduction}

$\mathrm{T}$ HE purpose of this paper is to introduce the concept of wind driven vehicles for planetary exploration. It starts with a history of wind driven land craft used on Earth. This is followed by an outline of current

* Aerospace Engineer, Architectures, Science, Missions Branch, Mail Stop 462, AIAA Member.

† Senior Principal Engineer, Advanced Thermal \& Mobility Technologies, Mail Stop 157-316, AIAA Senior Member.

‡ Senior Technical Staff, Robotic Vehicles Group, Mail Stop 198-235., AIAA non-member

${ }^{\S}$ Aircraft/Robotics coordinator, Education Department, 600 Settlers Landing Rd., AIAA non-member 
developments toward wind driven exploration vehicles. In past centuries the wind has propelled Earth explorers in their sailing ships around the world, making use of this unlimited natural resource. Land craft designed for wind propulsion have used sails, windmills and more recently the structure itself. The latter fall in the category of the 'Tumbleweed' rovers. Tumbleweeds are generally spherical constructs that roll across the planetary surface much as the tumbleweed plants roll across the steppes and prairies on Earth. The biomimetic design concept is to imitate nature. Natural systems are extremely efficient non-linear optimizers.

There is a current emphasis on the use of in-situ resources for planetary exploration systems. The wind is such a source of power without the need for chemical conversion or storage to drive exploration rovers. A power boat has unique capabilities, but relies on limited fuel or electric power to move the vessel. Like the sailing ships used by early explorers on earth, The Tumbleweed uses an unlimited resource - the wind to move around the surface of Mars.

Current exploration rover technology is based on the power vessel philosophy - a controlled application of stored energy. The Mars Exploration Rovers (MERs), Spirit and Opportunity, make a series of short distance highly controlled movements on the surface of Mars. This facilitates in-depth analysis of a small percentage of the planetary surface. The Tumbleweed exploration philosophy is to explore and survey large areas quickly and retrieve data that will indicate where in-depth analysis is needed.
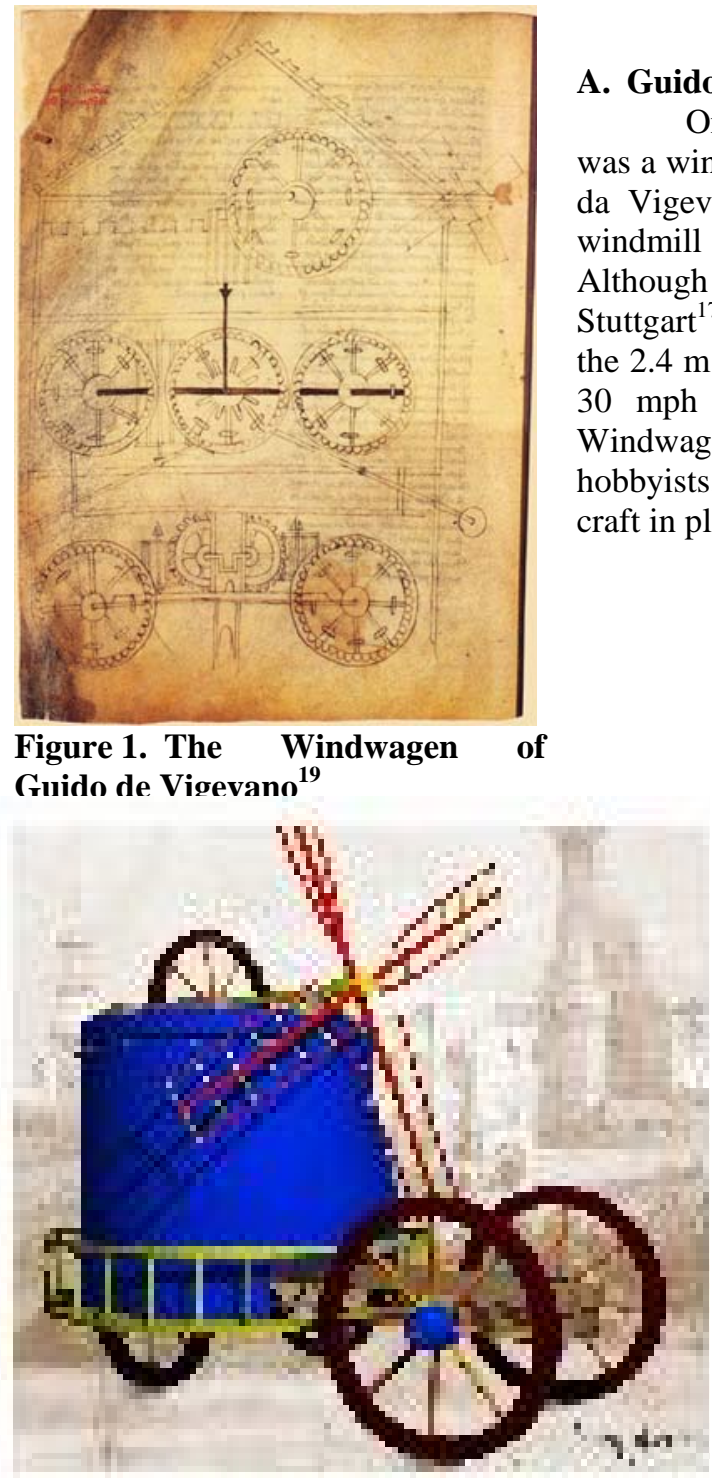

Figure 2. Windwagen depiction external view ${ }^{17}$,

\section{A History of Wind-driven land craft}

\section{A. Guido da Vigevano 1335 "Windwagon"}

One of the earliest documented wind propelled land craft was a windmill powered wagon designed by an Italian priest, Guido da Vigevano, for King Phillip VI of France in 1335 A.D. The windmill drives the wheels though a series of gears and shafts. Although never built, analysis performed at the University of Stuttgart ${ }^{17,25}$ estimated that the 6-8 $\mathrm{m}$ diameter windmill could drive the $2.4 \mathrm{~m}$ diameter wheels of the wagon to a top speed approaching $30 \mathrm{mph}$ directly into the wind. Modern derivatives of the Windwagen have been proposed in wind energy studies and by hobbyists. Further study will determine the usefulness of windmill craft in planetary exploration.

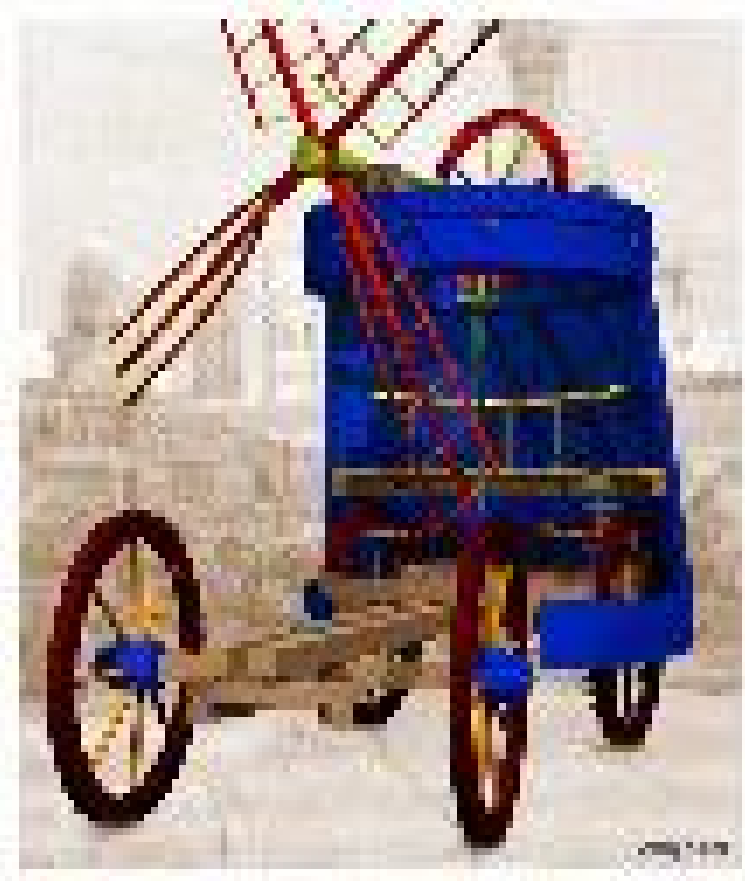

Figure 3. Windwagen depiction showing internal mechanisms ${ }^{17,25}$ 


\section{B. Early Land Sailors}

1. $16^{\text {th }}$ Century Dutch Sand Cars

Dutch mathematician Simon Stevin designed the Sand Cars depicted in this engraving from the 1500's, for Maurice of Nassau, Prince of Orange. These square-rigged wagons were capable of $25 \mathrm{mph}$; however, as with square-rigged ships, were only capable of down wind travel. These sand cars were used on smooth open beaches.

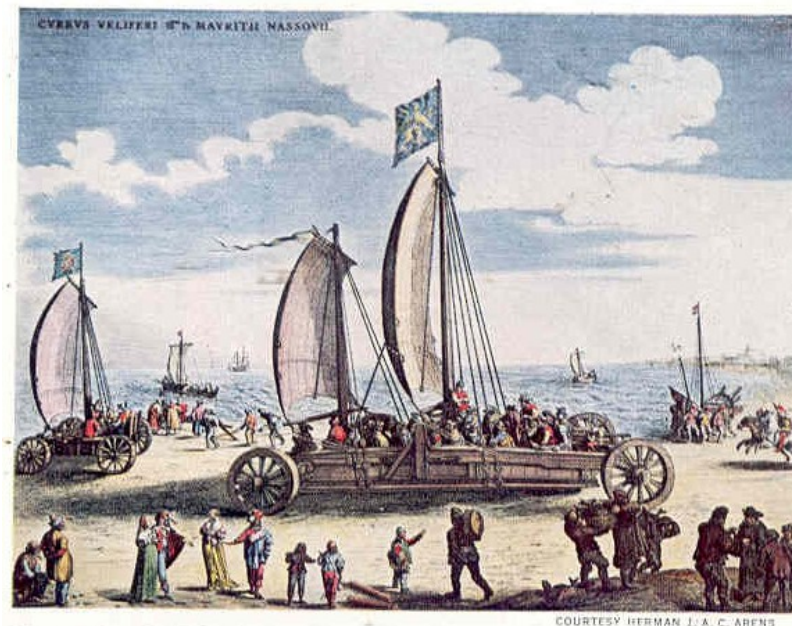

Figure 4. The Sand cars of Simon Stevin ${ }^{23}$

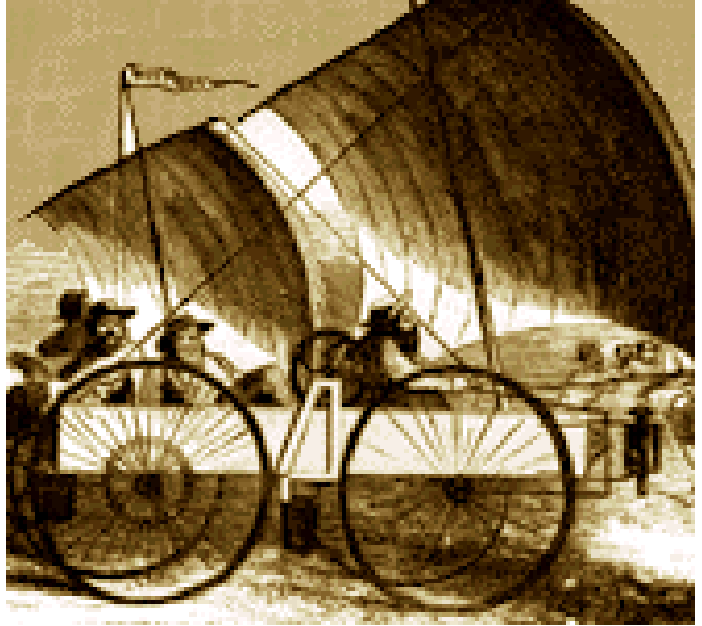

Figure 5. The Wind Wagon (circa1849) ${ }^{21}$

\section{The wind wagon of 1849}

The wind wagon of $1849^{21}$ was built to cross the American prairie during the California gold rush of 1849 . The wind wagon "attained a speed of $15 \mathrm{mph}$ " before losing control and crashing.

Although these examples were not used for long distance transportation, they were predecessors for modern land craft. In 1967, General Jean du Boucher, French Army retired, related his experiences on a trans-Saharan sailing expedition ${ }^{23}$ which shows the feasibility of crewed sail powered land craft for covering rough terrain.

\section{Modern Land Sailing Vehicles}

Land yachts use sailboat and aerospace technology to propel the craft across open desert terrain. These vehicles are well suited to the dry lake beds of the American West. Land yachting has produced wind driven craft that now exceed $115 \mathrm{mph}$ and can sail efficiently up wind. High performance modern land yachts use lightweight high efficiency airfoil "wing" sails to produce lift. These craft can reach (sail across the wind) at speeds that exceed the wind speed typically by a factor of four to one. Kite buggies are the play vehicles of the wind-powered craft. They use steerable kites tethered to the buggy for propulsion.

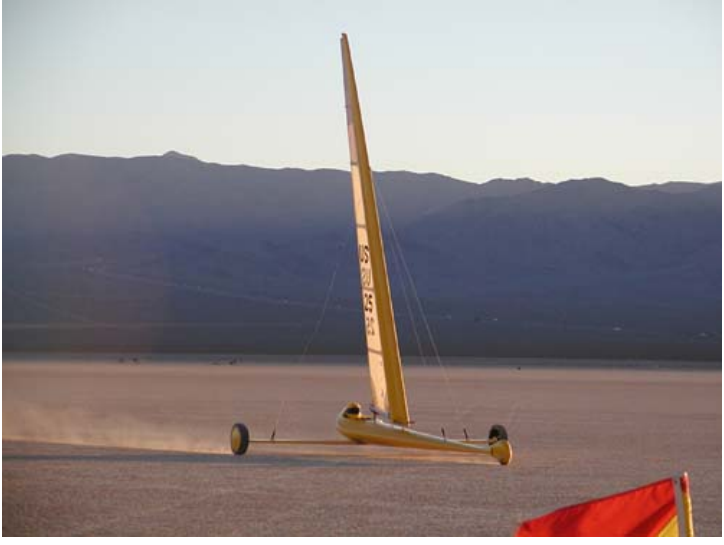

Figure 6. Alan Wirtanen's 2003 class III yacht ${ }^{22}$

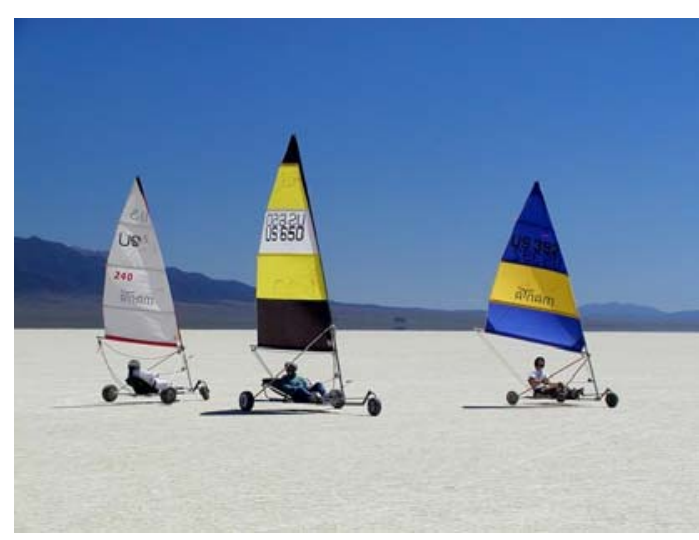

Figure 7. Manta class land sailors ${ }^{27}$ 


\section{Current Developments -The introduction of Tumbleweeds to Mars}

A simpler form of wind driven craft has recently come to the forefront - Tumbleweed Rovers. As the name implies the Tumbleweeds mimic the transportation mode of the tumbleweed plants as the whole vehicle rolls across the planetary surface with the wind. Designing for Mars presents challenges in accounting for the environmental conditions encountered on the Martian surface (Table 1). Although the gravity of Mars is approximately 1/3 that of Earth the much lower atmospheric density and pressure are more limiting factors.

Tumbleweeds landing sites are not as terrain limited as for other rover types. Smooth beaches, dry lakebeds or snowfields are not necessary for the efficient operation of Tumbleweeds. Rock strewn planes, canyons and craters are negotiable by these devices. Analyses ${ }^{1,13,16}$ have determined that $20 \mathrm{~kg}$ balls $6 \mathrm{~m}$ diameter could roll over or through rock fields found on Mars by the Viking and Pathfinder landers and Mars Exploration Rovers.

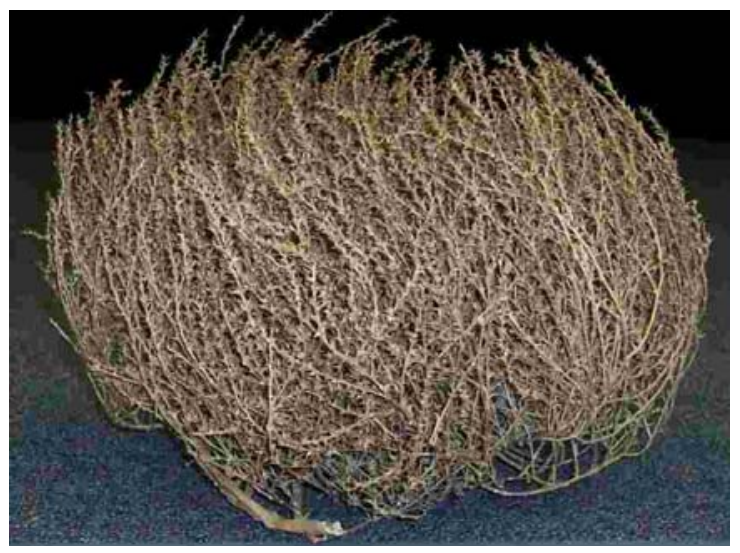

Figure 8. Tumbleweed plant used in the Langley Research Center studies

Table 1 Environmental considerations for Rover Design ${ }^{13}$

\begin{tabular}{|l|c|c|}
\hline & Earth & Mars \\
\hline Atmospheric Density & $1.217 \mathrm{~kg} / \mathrm{m}^{3}$ & $0.0155 \mathrm{~kg} / \mathrm{m}^{3}$ \\
\hline Atmospheric Pressure & $1014 \mathrm{mbars}$ & $6.4 \mathrm{mbars}$ \\
\hline $\begin{array}{l}\text { Average Temperature } \\
\text { Range }\end{array}$ & $-130 \mathrm{C}$ to $370 \mathrm{C}$ & $\mathbf{8 9 0 C}$ to $-310 \mathrm{C}$ \\
\hline $\begin{array}{l}\text { Major Atmosphere } \\
\text { Constituents }\end{array}$ & N2 (78\%), O2 (21\%) & $\mathrm{CO} 2(95 \%), \mathrm{N2}(3 \%), 02$ \\
\hline Gravity & $9.8 \mathrm{~m} / \mathrm{s}^{2}$ & $(0.13 \%)$ \\
\hline
\end{tabular}

With its low ballistic coefficient, the tumbleweed's calculated terminal velocity of a freefalling Tumbleweed rover in Mars atmosphere conditions is approximately $20 \mathrm{~m} / \mathrm{s}$, approximately the expected maximum speed of the tumbleweed rolling across the Mars surface. This would allow for in air deployment of the rovers opening vast areas to investigation inaccessible to other lander types. Canyons and cliffs present less danger to tumbleweeds which would roll down the walls to the bottom. Tumbleweeds could conduct investigations of canyon and gully formations for water or other biomarker content ${ }^{30}$ that are inaccessible to other rovers.

Early measurements indicated that Mars lacked a significant magnetic field. However, measurements from the relatively low altitude aerobraking phase of the Mars Global Surveyor mission indicated surprisingly strong magnetic anomalies in the Southern hemisphere. These anomalies appeared from orbital altitude as stripes, up to $2000 \mathrm{~km}$ long. Since the higher-order terms of the magnetic field are more strongly attenuated with distance, the nature of these anomalies has not been determined. ${ }^{29}$ Multiple Tumbleweeds carrying magnetometers within meters of the Martian surface could more precisely define the magnetic fields.

\section{Jet Propulsion Laboratories}

3. JPL Wind Driven Rover History

Jacques Blamont of JPL and the University of Paris conceived the first documented Mars wind-blown ball in 1977, shortly after the Mars Viking landers discovered that Mars has a thin CO2 atmosphere with relatively strong winds. Blamont's "Mars Balls" were conceived as relatively large, 3- to 10-meter diameter inflatable balls that could carry payloads, of $20-30 \mathrm{~kg}$ for distances of at least $100 \mathrm{~km} \mathrm{1,18.} \mathrm{These} \mathrm{proposed}$ balls could be powered by the wind or could be powered and steered by an inner drive mechanism. 
Ten years later, in 1987, the University of Arizona fabricated a large cylindrical device that was $4 \mathrm{~m}$ high by $5 \mathrm{~m}$ wide, and had a mass of 500kg (Figure 9). The University of Arizona "Mars Ball” could travel about $1 \mathrm{~m} /$ minute by means of alternately compressing and deflating the eight chambers surrounding the central payload. Unfortunately, the mass and power requirements of this device proved too large for

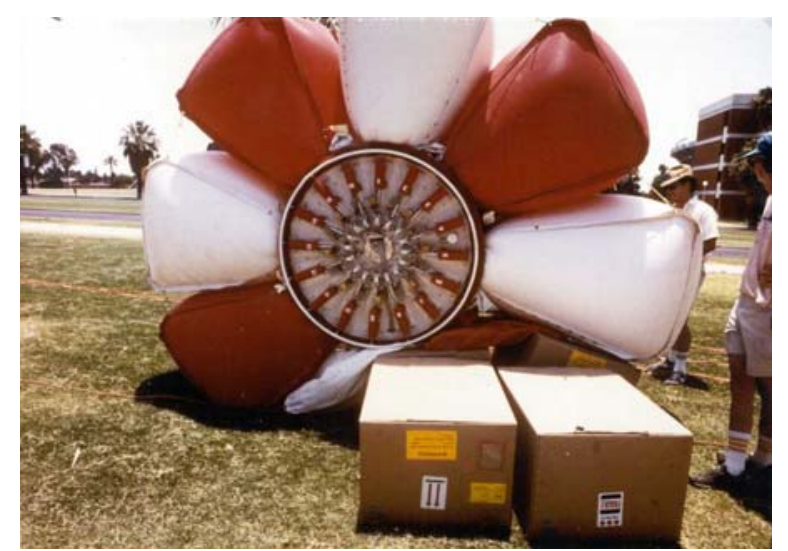

Figure 9. The University of Arizona "Mars Ball". realistic Mars applications. Although pneumatically driven this Mars Ball was not a truly wind driven rover.

Eight years later, in 1995, Jack Jones, et al, of JPL conceived of a large wind-blown ball for Mars that could also be driven and steered by means of a motorized mass hanging beneath the rolling axis of the ball. The motorized concept ${ }^{2}$ was abandoned when it was realized that the ball could inherently generate very little torque, and thus relatively small rocks easily trapped it. Jones then went on to develop a three-wheeled inflatable rover that could easily climb $0.5 \mathrm{~m}$ rocks, thus making it capable of quickly traversing well over 99\% of the Martian surface ${ }^{3}$.

In 2000, Jones was testing the threewheeled inflatable rover in a windy sand dune area in California's Mojave Desert when one of the wheels broke off and took off over the sand dunes while Jones' crew chased the ball with a dune buggy.

The renegade $1.5 \mathrm{~m}$ diameter ball was able to climb steep slopes, over large boulders, and through the jagged brush without hesitation. This seemingly unlucky incident produced a rather lucky discovery and was the inspiration for the current Tumbleweed rover ${ }^{4}$ The University of Southern California, under

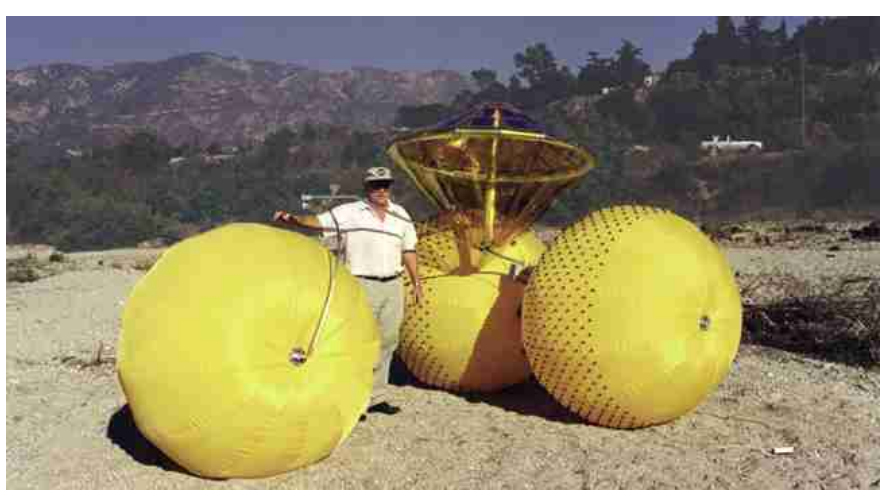

Figure 10. J. Jones Inflatable Tricycle Rover

contract to JPL, confirmed that a 6-m diameter 20-kg inflatable Tumbleweed was capable of climbing over large $1-\mathrm{m}$ rocks and up $20^{\circ}$ hills with moderately strong Martian seasonal winds of $20 \mathrm{~m} / \mathrm{sec}$. (Figure 3, Ref. 5). JPL then went on to confirm some of the USC theoretical analysis with tests on a $1.5 \mathrm{~m}$ sphere in the Mojave Desert.

Numerous other researchers have also suggested spherical rovers. Halme et al have constructed a spherical robot with a single wheel resting on the bottom of a spherical shell ${ }^{6}$. Bicchi, et al developed a robot consisting of a spherical shell with a small "car" resting on the bottom", Bhattacharya and Agrawal ${ }^{8}$ designed a spherical robot with three internal rotors. Bruhn et al developed a Spherical Mobile Investigator for Planetary Surface (SMIPS) concept that could roll and hop ${ }^{9}$ and is based on a Swedish patent held by Per Samuelson. Michaud and Caron have developed a spherical "Roball” similar to the SMIPS concept, except with a different location of motors ${ }^{10}$. An approach based on the distributed masses inside a spherical shell was introduced by Mukherjee, et $\mathrm{al}^{11}$ and implemented by Javadi, and Mojabi ${ }^{12}$. Further details of most of these concepts are described in an excellent summary paper by Bruhn, et all. ${ }^{8}$

4. Antarctic and Greenland Tests

Several deployments have been made with inflatable "Tumbleweeds" to some of the most trying conditions on planet Earth including a 130 kilometer, wind-driven trek across Antarctica. A Tumbleweed Rover, developed at NASA's Jet Propulsion Laboratory (JPL) left the National Science Foundation's Amundsen-Scott South Pole Station on Jan. 24, 2004 completing its roll across Antarctica's polar plateau roughly eight days later. Along the way, the beach-ball-shaped device, roughly 1.5 meters (4.5 feet) in diameter, used the global Iridium satellite communication network to send information about its position, the surrounding air temperature, pressure, humidity and light intensity to a JPL ground station. The test was designed to confirm the rover's long-term durability in an extremely cold environment, and reinforces the 
findings of a two other tests conducted on the Greenland ice cap. Current design refinements underway are focused on reducing the rover's weight and rolling resistance to lower the minimum winds needed to propel the rover and enable it to travel farther and adapting the payload to include a ground-penetrating radar or magnetometer to conduct ice surveys.

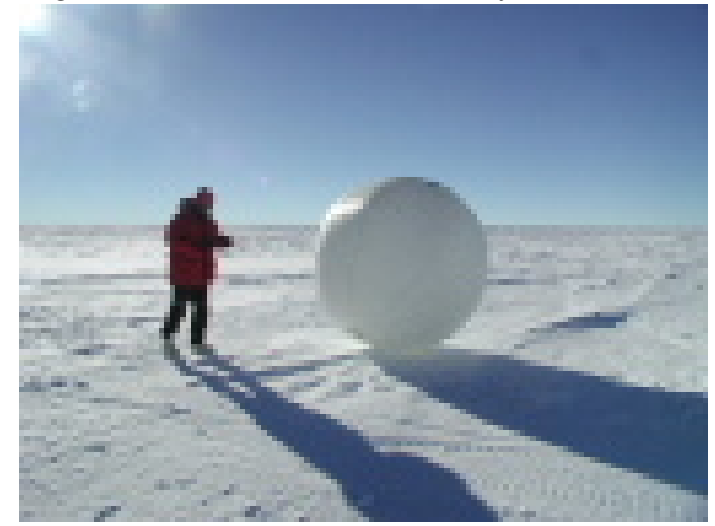

Figure 11. A. Behar, Tumbleweed release at Amundsen-Scott South Pole station

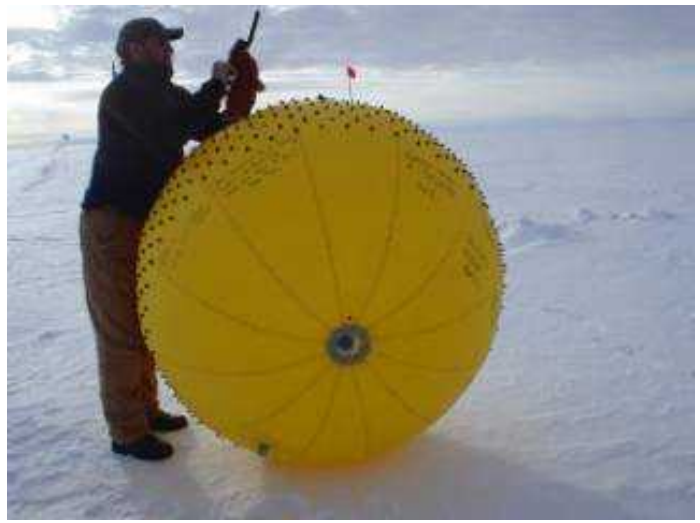

Figure 12. Tumbleweed prior to deployment from Summit Camp, Greenland ${ }^{4}$

\section{E. NASA Langley Research Center \\ 5. Introduction}

The Langley Tumbleweed Rover development started after the Pathfinder landing analysis. The Pathfinder lander traveled further bouncing and rolling on it's airbags in those few moments at landing than the Sojourner Rover traveled during it's entire 90 Sol mission. The question arose of what could be accomplished by maintaining the rolling motion. Proposed operational goals include traversing the surface of Mars to survey and map the minerals, gases, and liquids that are present as well as to obtain climate data. This survey could then be used to choose landing sites for the heavy analysis lab rovers such as the upcoming Mars Science Laboratory (MSL).

6. Concept development

The Langley Tumbleweed philosophy employed biomimetic theories in the design stages, primarily that

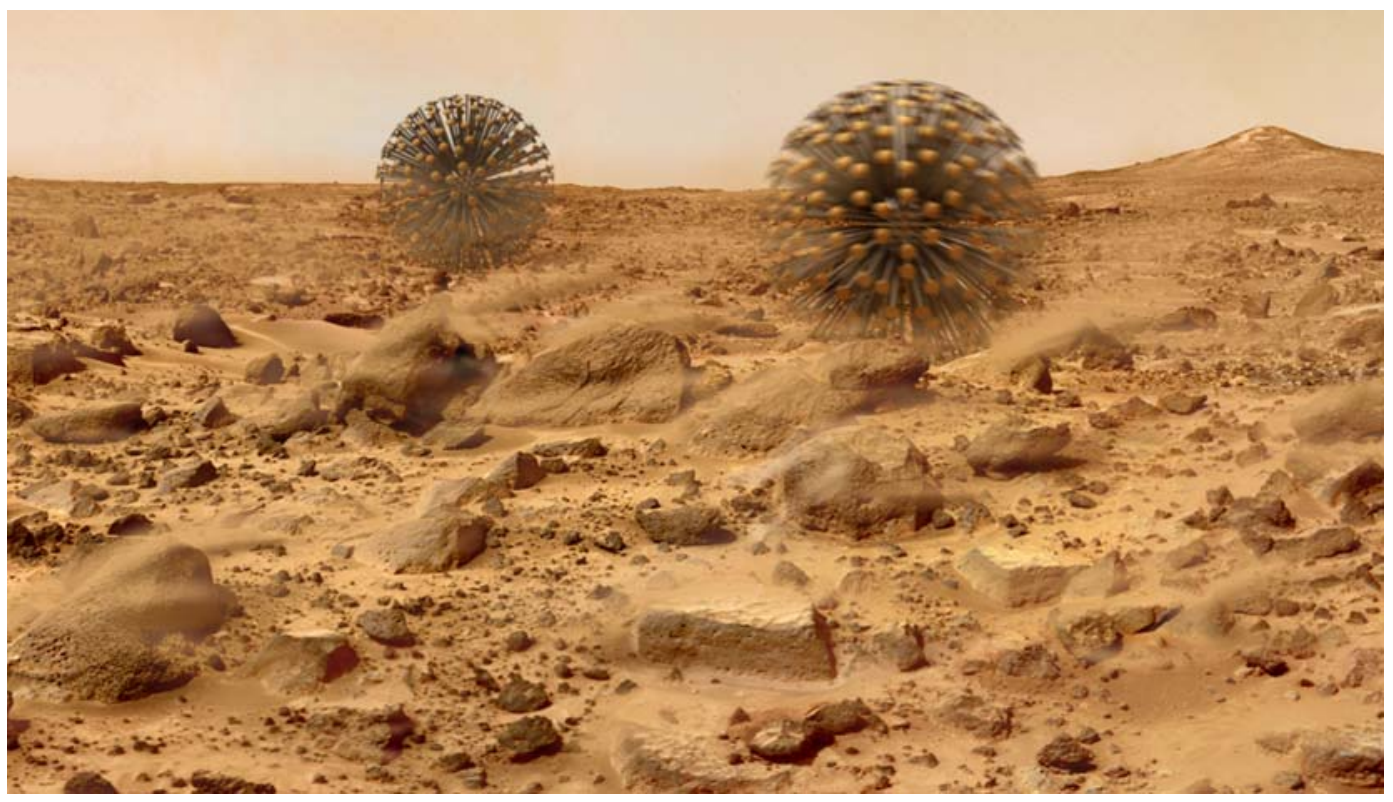

Figure 13. Artist's rendering of Dandelion Tumbleweeds traversing Mars

nature, being a highly efficient non-linear optimizer, has already pushed development of the desired characteristics in the tumbleweed plants. Emphasis was placed on replicating features from the plants, such 
as branchiating structures with aerodynamic features. The tumbleweed plants, Salsola genus, have multibranch fibrous composite hollow-core structures. Other designs used structures to deploy sail cloth.

The Tumbleweed designs must have a mass less than $20 \mathrm{~kg}$ for a 6 meter diameter, for the thin Martian air to provide sufficient aerodynamic force for sustained motion though a Mars rock field. ${ }^{5,13,16}$ These calculations are based on the aerodynamic drag coefficient of a smooth sphere. The Langley designs are a departure from the smooth inflated sphere designs of prior research.. TumbleCup, Dandelion and BoxKite are a few of the concepts.

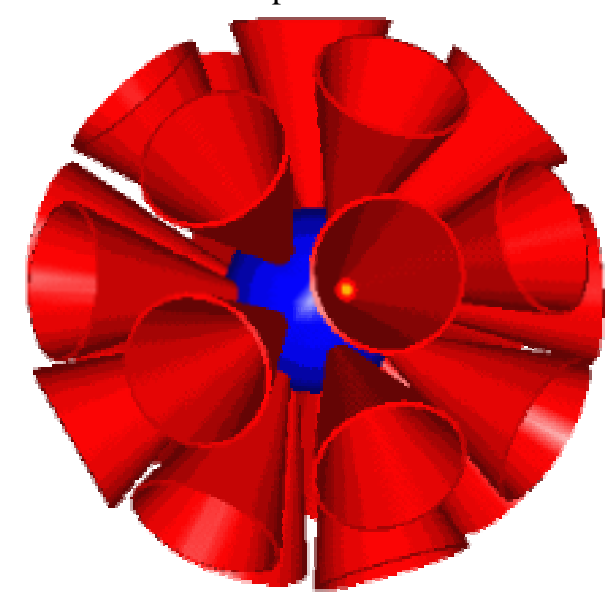

Figure 14. The 24 TumbleCup.

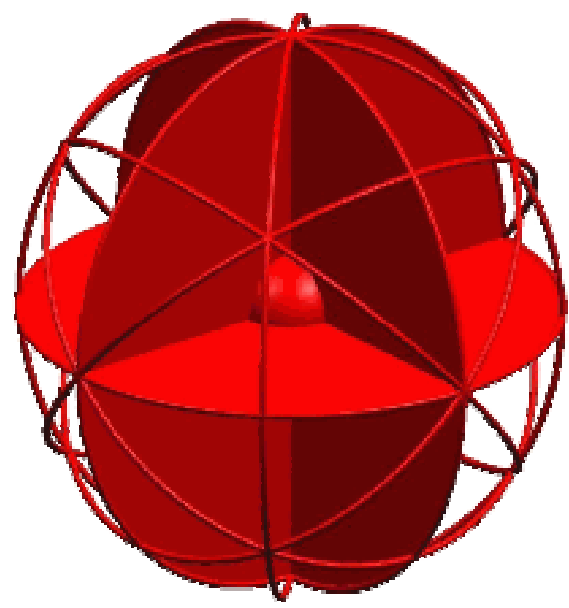

Figure 15. BoxKite with NCSU external strucutre

The Dandelion Concept has a central core containing the rover subsystems and multiple stems extending radially from the core. The stems have pads at the ends for shock attenuation and surface interface.

The TumbleCup was inspired from watching a foam cup blow across the parking lot. Through simple experiments it was determined that an array of cups around a core rolled and traveled better than a single cup. Wind tunnel tests were run to determine the number and proportions of cups to optimize the drag characteristics of the design. The BoxKite is composed of three intersecting orthogonal disks with an instrument pod in the center. The Langley BoxKite has thin fabric stretched over spring hoops.

7. Tumbleweed Wind Tunnel testing and Computational Fluid Dynamics (CFD) analysis

Wind tunnel tests performed at the Langley Basic Aerodynamics Research Tunnel (BART) were used to quantify the drag characteristics of the various tumbleweed designs. Several initial concepts tested at Langley included the TumbleCup, Dandelion and Box Kite. Wind tunnel tests have shown these designs to have a larger drag coefficient than the sphere for the expected flow conditions. The wind tunnel test results were run in conjunction with CFD analysis. The CFD analysis were of individual Tumbleweed parts as well as assemblies representing entire Tumbleweed structures such as the Box Kite and Dandelion. Future additional analysis will be needed to correlate the wind tunnel test data. Aerodynamic data for the Tumbleweed plant was inconclusive due to vibration modes that overwhelmed the balance.

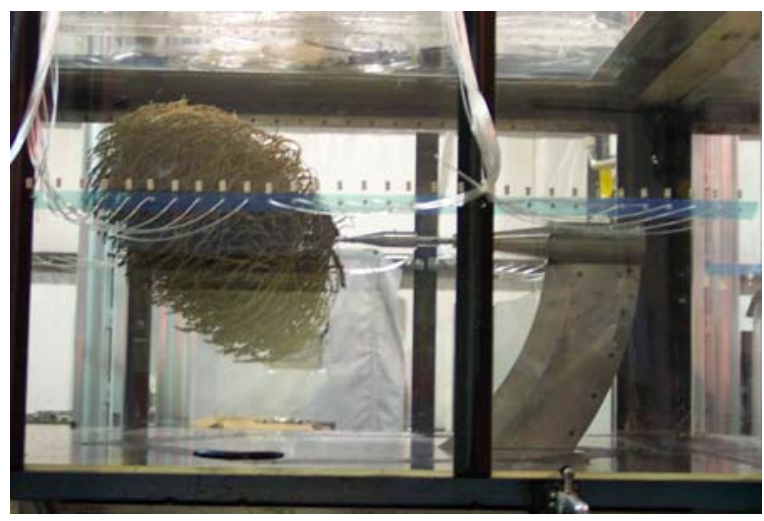

Figure 16. Testing the Tumbleweed in the BART

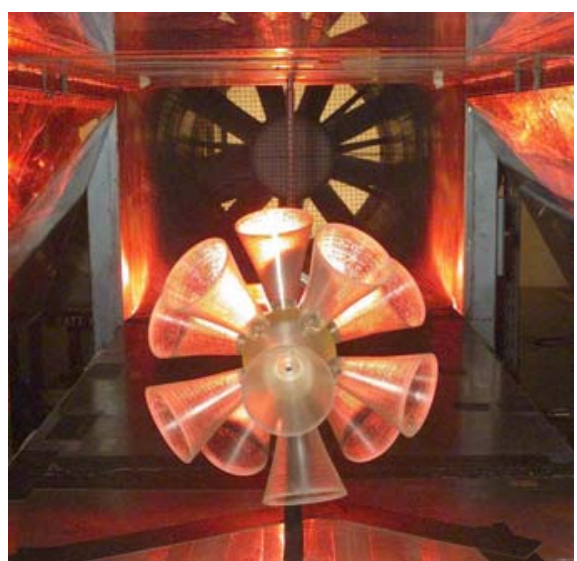

Figure 17. TumbleCup in the BART 


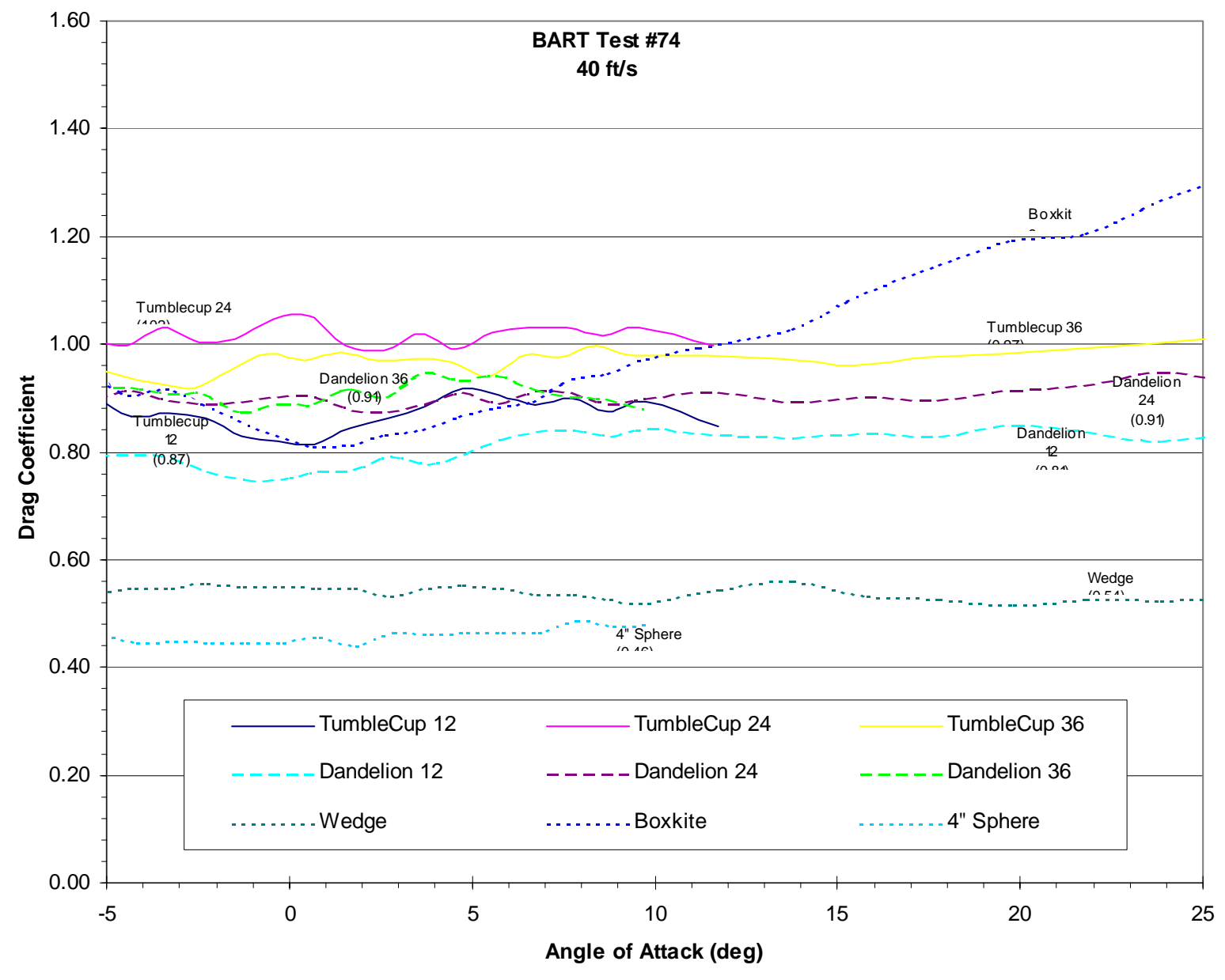

Figure 18. Preliminary Drag Coefficient vs. Angle of Attack results for Tumbleweed Models

8. Dynamics simulation, testing and analysis

Dynamic simulation software is under development at Langley Research Center to predict the path of Tumbleweeds rolling and bouncing across the surface of Mars. Rolling/bouncing dynamics tests using videogrammetry were conducted to better understand, characterize, and validate the dynamics model assumptions. Understanding the effects of structural non-linearity on rolling resistance in bouncing/rolling dynamic conditions was of particular interest in this examination. Tests were performed on an inflated ball, the caged Box Kite and a variation on the dandelion concept.

The dynamics test was conducted using cameras to monitor the dynamics of the model by capturing the motion of 32 targets affixed to the models outer structure. Proper placement of the cameras and alignment of their respective fields of view provided adequate image resolution of multiple targets along the trajectory as the model proceeded down the ramp. Image processing of the camera frames from multiple cameras allowed for target position determination accuracy on the order centimeters. Position data from a set of these test

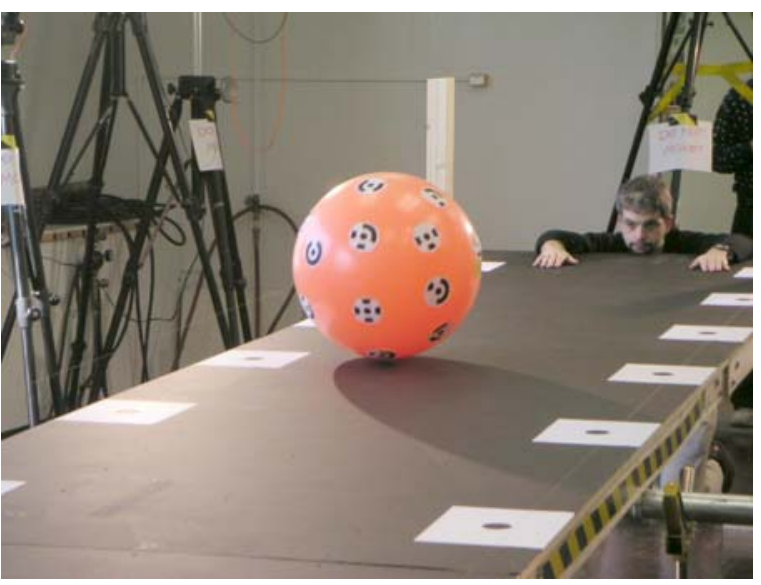

Figure 19. Targeted Calibration Sphere for the dynamics test series. 
runs was compared with results of a three dimensional, flexible dynamics simulation of the model. Model input parameters were adjusted to match the test data for various runs conducted during the test series. ${ }^{31}$

The Monte Carlo Tumbleweed Mission Simulator (MCTMS) software under development at Langley takes the dynamic simulation to the next level - mission simulation. Whereas the Dynamic simulator is used to verify the instantaneous dynamic properties and modes of the Tumbleweed, the MCTMS will be used to predict the probable path the Tumbleweeds will take after deployment. The MCTMS incorporates environmental data from past missions including the Mars Orbiter Laser Altimeter (MOLA) 1/128 degree resolution topographic data as well as Mars Global Reference Atmosphere Model (MarsGRAM) wind models.

Once the dynamics are understood it may be possible to control the motion of the Tumbleweeds. Several control techniques for the tumbleweed are under development, each applicable to specific Tumbleweed concepts. These will allow the Tumbleweeds to disperse to survey large areas, but to swarm together to more fully investigate interesting discoveries. In this manner a suite of instruments can be distributed over several rovers but brought together for synergistic analysis. ${ }^{32}$

9. Communications studies

Initial communication system studies for the Tumbleweeds indicate that the Mars orbiting assets (satellites) could provide a communication link to earth based researchers. Additional analysis will be needed to determine the extent of the data transmission for a tumbleweed in a canyon or crevasse or the effects of downloading data from multiple Tumbleweeds simultaneously. Reduction in the mass and power requirements of the communications system hardware would benefit the Tumbleweed rovers concepts.

\section{F. Other Tumbleweed efforts}

\section{Swiss Federal Institute of Technology Lausanne "Windball"}

Thomas Estier and Moritz von Heimendahl developed a Shape Memory Alloy (SMA) actuated tumbleweed-like Windball while studying at the Swiss Federal Institute of Technology Lausanne. The Windball used the daily temperature variations for deployment from its resting configuration of concentric loops to a spherical displacement configuration for traversing the Martian terrain, and to collapse into recharge/data gathering mode, repeating this cycle each Sol. ${ }^{15}$ Their work suggested two configurations a rigid structured "Hardball" and an inflated "Softball". The Hardball structural elements would use SMA actuators for deployment. The Hardball is structured as three orthogonal circular flat plates, similar arrangement to the BoxKite, enclosed in a cage structure formed of SMA. Heimendahl discusses several candidate mechanisms for deployment of the Softball. Wind channel tests were performed to determine and compare aerodynamic characteristics of the models at various wind incidence angles. Rolling tests on a scaled Mars surface simulate indicated the relative ability of the models to traverse the Martian landscape. Gravel and small stones were placed on a tapestry to create a Viking Lander site rock field distribution. ${ }^{16}$

\section{Texas Tech University (TTU)}

The TTU Tumbleweed concepts (Figure 19-21) were developed as a senior Mechanical Engineering design class project. The research is being continued through a grant from the Texas Space Grant Consortium and will involve the TTU Wind Science and Engineering Research Department as well as the MEMS Sensor Center at TTU. Dr. Alan Barhorst is leading the activity. ${ }^{19}$ A collaborative effort between TTU and LaRC investigated the Mars wind surface boundary layer model. A boundary layer simulating a scaled Mars estimated boundary layer was set up in the TTU wind tunnel to test the TTU Tumbleweed

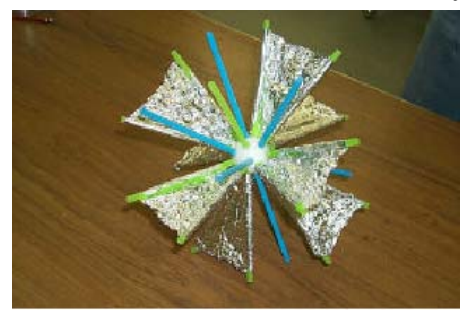

Figure 20. Texas Tech Tumbleweed Concept 1 concept models and the Langley Concept models.
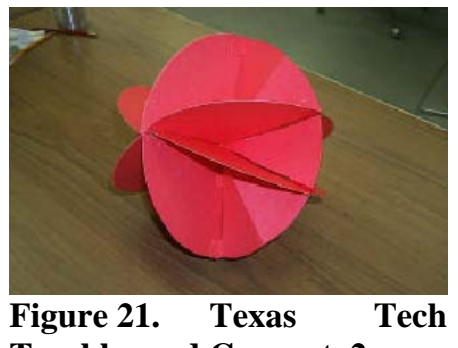

Tumbleweed Concept 2

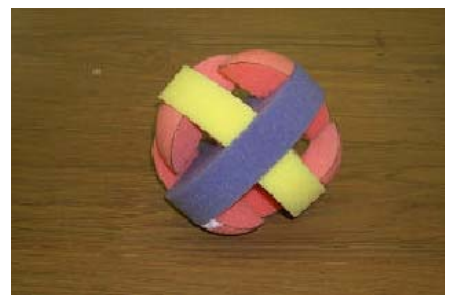

Figure 22. Texas Tech Tumbleweed Concept 3 


\section{North Carolina State University(NCSU)}

The Mars Tumbleweed Design Project is a collaboration between the NASA Langley Research Center's Spacecraft and Sensors Branch and the North Carolina State University (NCSU) Aerospace Engineering Space Senior Design Class. The NCSU Space Senior Design Class is headed by Dr. Fred DeJarnette.

The project started as a two-semester "design and build" project. During the first semester, the basic concepts were investigated, analyzed, and the Tumbleweed vehicle was designed. During the second semester, a proof-of-concept vehicle was built and operated. The final vehicle design process included testing a deployment method, payload data collection capabilities, communication concepts, and limited controls (ability to start and stop for data collection, if needed).

Lessons learned from the design, manufacture, and demonstration of the proof-of-concept vehicle will be provided to NASA for further studies into the concept. ${ }^{24}$

The students in the first team presented their results at Langley

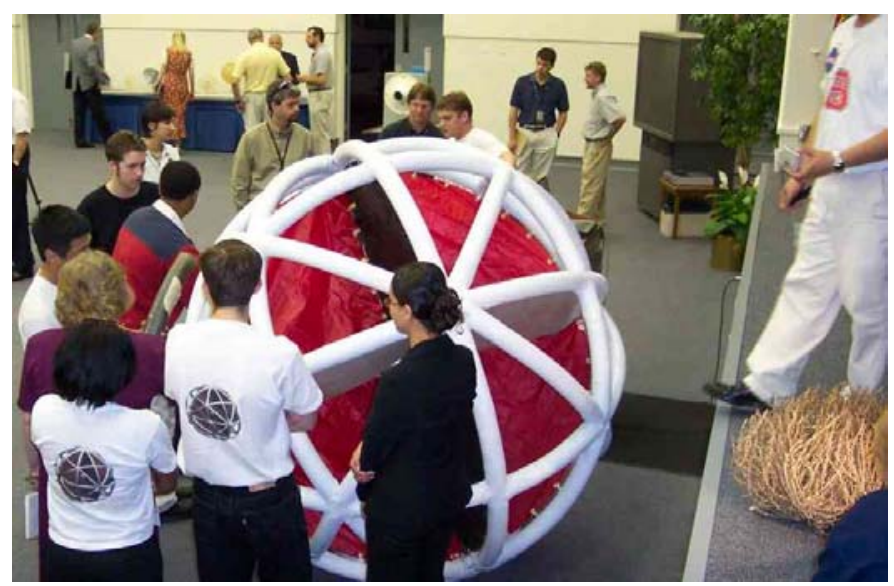

Figure 23. NCSU students prepare the TED for a demonstration at Langley Research Center.

Research Center on May 14, 2003. The presentation included deployment of the Tumbleweed Earth Demonstrator (TED). The TED is a variation of the BoxKite design. An external cage structure was added to reduce the rolling resistance of the TED. The NCSU design uses inflatable and rigidizable tubes to form the cage structure. This eases compact stowage and deployment.

Studies in the spring of 2004 included deployment, navigation and power systems. Fall semester studies continue to refine the designs. Another phase of tumbleweed development is underway at NCSU for the 2004-2005 school year.

The Sixth Grade science classes of Fred J. Carnage GT Magnet Middle School in Raleigh, North Carolina participate in an outreach program through their teacher, Holly Hanrahan. Ms. Hanrahan is a Kenan Fellow at North Carolina State University. By working with the Aerospace engineering design class at NCSU, the Carnage students learn about aerodynamics, structures and other engineering disciplines needed to build planetary exploration systems.

\section{Other Current Developments in Wind Rovers}

\section{A. The Dodd Mars Sailor}

Mike Dodd, Virginia Air and Space Center, has been testing a design for a Mars Sailor based on some of the historical land sailor developments (Fig. 23, 24). His design with a low aspect-ratio, rigid sail plan folds compactly to the cart for launch. The short triple mast rig lowers the tipping moment of the sails to enhance vehicle stability over rough terrain. Further stability is gained by widening the wheel track. The current wing sail design articulates over 90 degrees. This allows feathering the sails to accentuate roll, yaw and speed control. In tests on three surfaces, smooth tennis courts, rough asphalt and dry dirt, the demonstrator model achieved speeds of 20 $\mathrm{mph}$ in $8 \mathrm{mph}$ winds. Rolling commenced with 2 mph winds on the smooth surfaces. On the higher friction surfaces $4 \mathrm{mph}$ winds were needed to

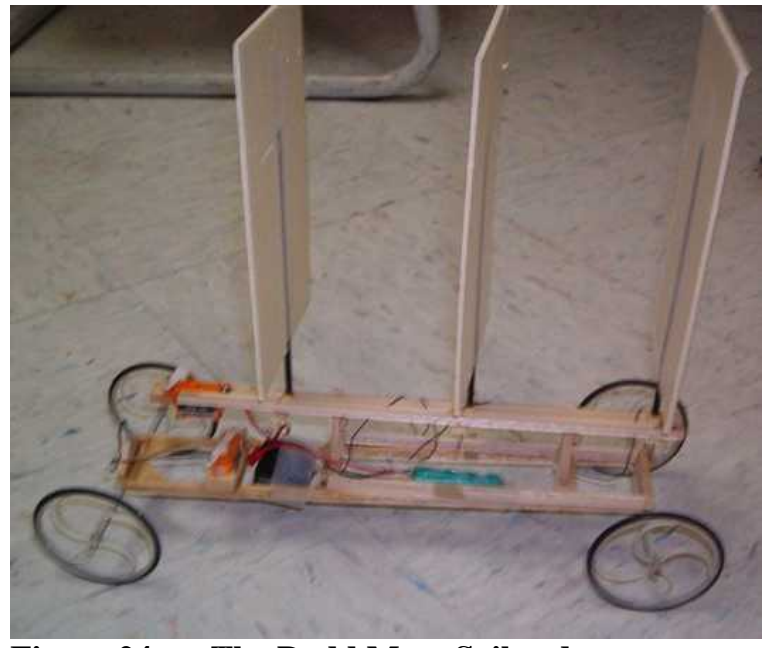

Figure 24. The Dodd Mars Sailor demonstrator 


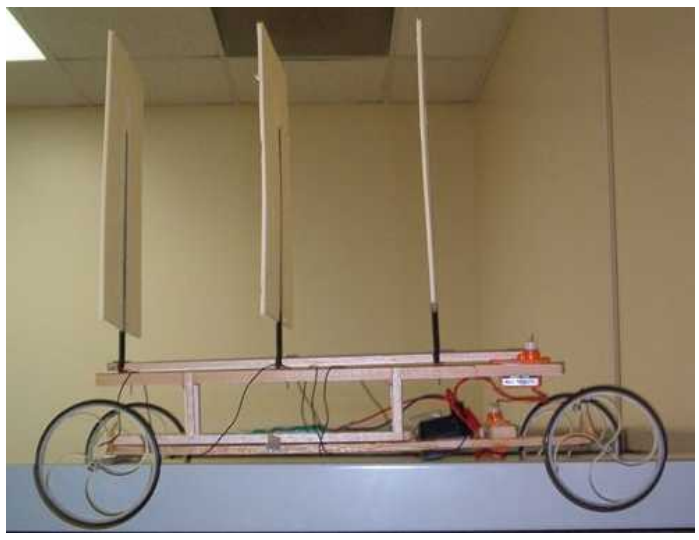

Figure 25. Dodd Mars Sailor demonstrator side view.

Balloons and dirigibles have been proposed to enhance surface area coverage of exploration vehicles., ${ }^{3,26}$ The Rand Corporation studied the use of balloons to explore Mars in the early 1960's. Jacques Blamont, chief scientist at the French Centre Nationales d'Etudes Spatiales (CNES), in 1987 suggested using a Montgolfiere solar heated balloon, anchored by a guide rope from below and a small helium balloon from above. Heated by the Sun, the balloon would soar during the day, traveling hundreds of miles and collecting data. At night its guide rope would lay on the ground, with the Montgolfiere held aloft by its smaller helium partner. ${ }^{26}$ A guide rope and sail technique was used by the Solomon A. Andree Polar Expedition in an attempt to fly a balloon over from Sweden to Alaska over the North Pole in 1897. This technique allowed for control of the balloon up to 30 degrees off of the true wind direction ${ }^{28}$ and could be used to control planetary exploration balloons.

Currently, studies are being conducted by JPL, the NASA Wallops Flight Facility (WFF) and GSSL, Inc. and Pioneer Astronautics on the use of wind driven balloons for planetary surface exploration. The Mars Solar Balloon Lander (MSBL) is a system, which uses a solar balloon, with or without a lighter-than$\mathrm{CO}_{2}$ float fluid, as a system for landing payloads on the surface of Mars. This technology has been developed for JPL by Pioneer Astronautics as part of a 2004 SBIR Program. Once the payload is delivered, the balloon can detach for an independent remote sensing flight mission, deployment of additional payloads elsewhere, or remain attached to the lander to provide such useful functions as local aerial survey, communications, or towing. Under this SBIR contract a new type of Mars surface mobility system called the two-wheeled chariot (TWC) for use in conjunction with the MSBL was developed and successfully field tested in high winds on both steep dunes and rocky terrain that would be impassible by conventional surface rovers. The TWC is towed along the surface by the wind driven balloon. ${ }^{33}$

\section{Conclusions}

Studies indicate that wind power is a viable resource for planetary surface exploration on planets and moons with atmospheres. The Tumbleweed Rovers under investigation by various institutions show promise of complimenting other investigations techniques for gathering data about Mars, as they fill a niche between orbiters and other rover types. With the low mass of Tumbleweeds many could be sent on a single launch vehicle. This would facilitate a surface survey mission covering a larger area.

\section{Acknowledgments}

The LaRC author would like to thank Dennis Bushnell and the NASA Langley Research Center (LaRC) Creativity and Innovation (C\&I) initiative for support of the Tumbleweed rover concept research. 


\section{References}

${ }^{1}$ Blamont ,J. , Jet Propulsion Laboratory, California Institute of Technology, Private Communications, 1977.

${ }^{2}$ Jones, J. A. and Yavrouian, A., JPL New Technology Report \#9894-20283, 1997.

${ }^{3}$ Jones, J. A., "Inflatable Robotics for Planetary Applications", $6^{\text {th }}$ International Symposium on Artificial Intelligence, Robotics and Automation in Space, I-SAIRIS, Montreal, Canada, June 19-21, 2001

${ }^{4}$ Behar, A., Jones, J. and Carsey, F., “NASA/JPL Tumbleweed Polar Rover”, IEEE Aeroconference, Big Sky Montana, March, 2004

${ }^{5}$ Wang, H., Yang, , B. and Jones, J. “Mobility Analysis of an Inflated Tumbleweed Ball under Wind Loads,”, AIAA Gossamer Spacecraft Forum, 2002.

${ }^{6}$ Halme, A., Schonberg, T., and Wang, Y. “Motion Control of a Spherical Mobile Robot”, Proceedings of the AMC’96 MIE, 1996.

${ }^{7}$ Bicchi, A. Balluchi, A., Prattichizzo, D. and Goreli, A., "Introducing the Spericale” IEEE International Conference on Robotics and Automation, April, 1997, pp. 2620-2625.

${ }^{8}$ Battacharya, S. and Agrawal, S.K., "Design, experiments and motion planning of a spherical rolling robot”, IEEE Internation Conference on Robotics and Automation, April, 2000, pp. 1208-1212.

${ }^{9}$ Fredrik Bruhn et al, publication pending in “IEEE Transactions in Robotics”, 2005.

${ }^{10}$ Michaud, F. and Caron, S., “Roball, the Rolling Robot”, Autonomous Robotics, vol 12, 2002, pp 211-222

${ }^{11}$ Mukherjee, R., Minor, M.A. and Pukrushpan, J.T., "Simple Motion Planning Strategies for Spherobot," $38^{\text {th }}$ Conference on Decision and Control, Phoenix, Arizona, Dec, 1999, pp. 2132,-2137

${ }^{12}$ Javadi, A.H. and Jojabi, P., “Introducing Augist”, 2002 IEEE International Conference on Robotics and Automation, Washing DC, May, 2002, pp. 3527-3533.

${ }^{13}$ Jeff Antol, J., Calhoun, P., Flick, J., Hajos, G., Kolacinski, ,R. Ph. D., Minton, D., Owens, R., Parker, J. “Low Cost Mars Surface Exploration: The Mars Tumbleweed”, NASA TM-2003-212411, August 2003

${ }^{14}$ da Vigevano, Guido, et al., Texaurus regis Francie

${ }^{15}$ Estier, T. and Siegwart, R. "Innovative Locomotion Concept for Long-Range Mission and Study of Martian Wind,“ Proceedings of the Sixth ESA Workshop on Advanced Space Technologies for Robotics and Automation, The Netherlands, December 5-7, 2000

${ }^{16}$ Von Heimendahl, M., “Windball,” Swiss Federal Institute of Technology Lausanne, December 3, 2001

${ }^{17}$ Dr. Alertz, U, RWTH Aachen, Germany Historisches Institut, Lehrstuhl für Mittlere Geschichte.

${ }^{18}$ Janes, D. M. “The Mars Ball: A Prototype Martian Rover” (AAS 87-272). The Case For Mars III, Part II - Volume 75, AAS Science and Technology Series, Eds. Carol R. Stoker, 1989, pp. 569-574.

${ }^{19}$ Hille, C., Moody, C., Rose, S., Kerr, K., “Wind Powered Martian Robot - Midterm Report”, College of Engineering, Texas Tech University, November 5, 2001.

Hajos, G., http://centauri.larc.nasa.gov/tumbleweed

${ }^{21}$ Trinklein, M. and Boettcher, S. “The Oregon Trail,” http://www.isu.edu/\%7Etrinmich/wagons.html , [Cited November 26, 2004]

\footnotetext{
${ }^{22}$ North American Land Sailing Association, http://www.nalsa.org/images/Ivan03/AMC00003_2/pages/US25_2.htm, [Cited
} 26 November 2004] 
${ }^{23}$ du Boucher, J., General de Brigade, French Army Retired, “Dry-Land Fleet Sails the Sahara”, National Geographic, Vol. 132, No. 5, Nov. 1967, pages 696-725

${ }^{24}$ Minton, D., et al., "Mars Tumbleweed, Preliminary Design Review”, North Carolina State University, Dept. of Mechanical and Aerospace Engineering, Raleigh, NC, USA, Nov. 2002

${ }^{25}$ Heiner Dörner, http://www.ifb.uni-stuttgart.de/ doerner/ewindenergie1.html, [Cited 21 October 2004]

${ }^{26}$ Alexander, A. "Mars Balloon Flies Again,” The Planetary Society, Sept 7, 2000, http://www.planetary.org/html/news/articlearchive/headlines/2000/marsballon.html , [Cited 13 December 2004]

${ }^{27}$ Harris, M., http://community.webshots.com/user/landsail , [Cited 20 December 2004]

${ }^{28}$ Cross, W. and Thorleif Hellbom, T., "Last Balloon to Nowhere" True Magazine. August 1962.

${ }^{29}$ Lorenz, R. D., Jones, J. A., Wu, J. J., “Mars Magnetometry from a Tumbleweed Rover”, IEEEAC paper \#1054, Dec 10, 2002

${ }^{30}$ Antol, J., Heldmann, J. L., “Using Wind Driven Tumbleweed Rovers to Explore Martian Gully Features”, Astrobiology Science and Technology Workshop, Sept. 2004

${ }^{31}$ Calhoun, P. C., Harris, S. B., Raiszadeh, B., Zaleski, K. D., "Conceptual Design and Dynamics Testing and Modeling of a Mars Tumbleweed Rover", AIAA-2005-0247, 43rd AIAA Aerospace Sciences Meeting and Exhibit, Reno, NV, January 10-13, 2005.

${ }^{32}$ Richard M. Kolacinski, R. M., Palmer, D. W., Patrick M. Cloutier and Jason E. Schatz, "Biologically Inspired Design for Low Cost Exploration of Space: Swarms of Martian Rovers Based upon the Russian Thistle, Proceedings of the 7th World Multiconference on Systemics, Cybernetics and Informatics 11 (2003): 32-38.

${ }^{33}$ Jones, J. A., Fairbrother, D., Lemieux, A., Zubrin, R., “Wind-Driven Montgolfiere Balloons For Mars ", AIAA-20050247, 43rd AIAA Aerospace Sciences Meeting and Exhibit, Reno, NV, January 10-13, 2005. 